\title{
Epidemiology of Inflight Medical Events
}

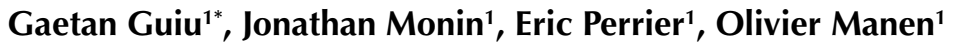 \\ ${ }^{1}$ Aeronautical Expertise Department, Percy Military Hospital, French Military Health Service, Paris, France
}

Corresponding Author: Gaetan Guiu, MD, Assistant Professor, Aeronautical Expertise Department, Percy Military Hospital, French Military Health Service, 101 avenue Henri Barbusse 9140 Clamart, Paris, France. Tel: +33-141467035, Email: gaetanguiu@hotmail.com

Received October 1, 2018; Accepted January 15, 2019; Online Published January 30, 2019

\begin{abstract}
Introduction: Since the 1950s, air travel has grown exponentially. In 2018, the number of international air passengers was estimated at 4.1 billion. Air travel exposes the passenger to a number of constraints (like physical constraints, stress) that can be correlated and lead to an inflight medical event, especially for passengers with chronic conditions or fragile health.

Methods: In June 2017, a mini review of the literature was conducted in order to summarize the data on inflight medical events and their frequency, types, and consequences.

Results: The most frequent inflight medical events are syncope and lipothymic discomfort, followed by digestive disorders, cardiorespiratory symptoms, neuropsychiatric disorders, and trauma. In almost two-thirds of all cases, these medical events are linked to a pre-existing pathology. There is no reliable register of inflight medical events, but their number is estimated to be between 120 to 350 each day throughout the world.

Conclusion: The definition of an inflight medical event deserves to be specified, and the collection of these events needs to be standardized. This will help bring about a better understanding of the issue and maybe raise awareness among passengers with chronic diseases or fragile health and their general practitioners.

Keywords: Epidemiology, Digestive System Diseases, Syncope
\end{abstract}

Citation: Guiu G, Monin J, Perrier E, Manen O. Epidemiology of inflight medical events. Int JTravel Med Glob Health. 2019;7(1):10-12. doi:10.15171/ ijtmgh.2019.03.

\section{Introduction}

Since the 1950s, air travel has grown exponentially. ${ }^{1}$ According to the International Air Transport Association, the threshold of three billion international travelers was crossed in $2013 .^{2}$ In 2018, the number of international air passengers was estimated at 4.1 billion, ${ }^{3}$ and almost as many passengers took domestic flights (3.4 billion in 2015). ${ }^{4}$ In the last past years, air travel has grown an average of 5.5\% per year. ${ }^{5}$ If the growth continues at that rate, the outlook for 2037 is nearly 15 billion air passengers, half of them on international flights. ${ }^{6}$ Although often associated with leisure and vacation, air travel exposes passengers to a number of constraints (like stress, fatigue, physical constraints) that can be correlated and can lead to inflight medical events, especially for passengers with chronic conditions or fragile health. The main objective of this article is to take stock of medical events occurring on commercial flights, their frequency, and their types.

\section{Methods}

In June 2017, a mini review of the literature was conducted using the web search engines Google, Google Scholar,
Pubmed, and Science Direct and the keywords "inflight medical emergencies" and "medical events and commercial airlines flights". Only articles describing medical events occurring on commercial flights and their frequency of occurrence were included in this study. Case reports as well as articles dealing exclusively with medical kits on airliners were excluded. Articles of interest were studied, and the authors attempted to summarize the data on the frequency of these events, their types, and their consequences.

\section{Results}

General Considerations on Inflight Medical Events

Three quarters of inflight medical events occur on longhaul flights. ${ }^{6,7}$ A large majority of the medical events are not serious. ${ }^{6-10}$ In almost $70 \%$ of situations, medical advice is obtained onboard, ${ }^{6,7}$ often by a doctor-passenger ( $40 \%$ to $48 \%$ of events), but also by a nurse (20\%-25\%) and even other health professionals.

The causes of inflight medical events from most common to least common are ${ }^{6,7,11}$ :

- Discomfort, faintness and syncope, which represent

Copyright $(0) 2019$ The Author(s). This is an open-access article distributed under the terms of the Creative Commons Attribution License (http:// creativecommons.org/licenses/by/4.0), which permits unrestricted use, distribution, and reproduction in any medium, provided the original work is properly cited. 
between $37 \%$ and $50 \%$ of these events and are usually caused by orthostatic hypotension or a vasovagal phenomenon $^{6,7,11,12 \text {; }}$

- Digestive disorders ( $13 \%$ to $15 \%)$, which in a large majority of cases is abdominal pain most likely caused by the expansion of digestive gas related to hypobaria;

- Respiratory symptoms (3.5\% to $12 \%$ ), like dyspnea caused by an asthma attack, for example;

- Cardiac symptoms (5.6\% to $8 \%)$, dominated by chest pain $^{6,7,11,13}$;

- Neuropsychiatric problems (3\% to $11 \%)$, the frequency of which is probably underestimated ${ }^{6,7,11}$; cases of agitation represent real security problems onboard particularly because of the risk of aggression towards other passengers and crew members; and

- Traumatic events ( $2 \%$ to $10 \%$ ), including minor injuries, which are probably underestimated. , $^{6,11,13}$

Table 1 shows the data from three important studies.

In about two-thirds of cases, inflight medical events are related to a pre-existing pathology, particularly cardiorespiratory issues. ${ }^{14,15}$

\section{Inflight Death}

According to the data from the literature, cardiac arrest complicated $0.3 \%$ to $1.3 \%$ of inflight medical events, ${ }^{6-10}$ which would represent approximately 1000 deaths worldwide each year; that is between 2 and 3 deaths each day. During flight, the survival rate after cardiac arrest is estimated between $14 \%$ and $55 \%,{ }^{16,17}$ with the highest rates comprising cases of ventricular fibrillation.

\section{Diversion}

Most inflight medical events do not involve a diversion. Only $3 \%$ to $13 \%$ of cases require the flight to be diverted. ${ }^{6,7,15,18,19}$ In more than two-thirds of cases, passengers over 50 years old are involved. The main causes of diversion are ${ }^{6,7,15,18,19}$ cardiorespiratory problems, neurological deficits, gastrointestinal disorders, a syncope, and gyneco-obstetric events.

After landing, the passengers who presented a problem onboard are sent to airport medical services, present in most major airports. It appears that in about $25 \%$ of cases, the patient is referred to a hospital for further examination and that in $8 \%$ of cases the patient is hospitalized for several days, particularly in cases of cardio-respiratory problems. ${ }^{6}$

Table 1. Types of Inflight Medical Events

\begin{tabular}{llll}
\hline Studies & ${\text { Peterson et } \mathrm{al}^{6}}$ & Sand et $\mathrm{al}^{7}$ & ${\text { Graf et } \mathrm{al}^{11}}^{11}$ \\
Years & $2008-2010$ & $2002-2007$ & $2000-2011$ \\
Inflight medical event (n) & 11929 & 10189 & $>20000$ \\
\hline Faintness & $37.4 \%$ & $53.5 \%$ & - \\
Digestive disorders & $13.6 \%$ & $8.9 \%$ & $34 \%$ \\
Respiratory symptoms & $12.1 \%$ & $3.9 \%$ & - \\
\hline Cardiac symptoms & $8 \%$ & $4,9 \%$ & $43 \% *$ \\
\hline Neuro-psychiatric disorders & $11.2 \%$ & $8 \%$ & - \\
\hline Traumatology & $1.8 \%$ & $3.3 \%$ & $12 \%$ \\
\hline
\end{tabular}

* $43 \%$ include cardiac symptoms, faintness and neuropsychiatric disorders.

\section{Discussion}

There is no standardized national or international register allowing a reliable collection or clear reading of inflight medical events. ${ }^{6,18}$ Nevertheless, few authors have been interested in this topic thanks to data from an airline or a medical aid company. ${ }^{6,7}$ However, it is often difficult to exploit or compare the data for several reasons, including the lack of a single and consensual definition of an "inflight medical event", the probable underestimation of the frequency of these medical events, and a lack of homogeneity in the collected data, which could lead to the same symptom being listed differently, with variable nuances. The diagnostic tools onboard a plane are limited, and the retrospective data is most often missing, which explains why these medical events are not presented by diagnoses, but by categories of symptoms or organ problems.

In the early 2000s, it was estimated that every day on airliners around the world 350 medical events occurred. ${ }^{20}$ This number probably is an overestimation of the reality, as it depends on the events taken into account. The authors of a recent study published in the New England Journal of Medicine in $2013^{6}$ used the results they obtained from data provided by several airlines to extrapolate the number of inflight medical events. Their estimate was close to 120 medical events occurring every day around the world. They probably underestimated the reality, especially because they only took into account events requiring medical advice from a ground aid service. It seems reasonable to estimate the number of medical events occurring in the air around the world each day as between 120 and 350 .

The number of deaths each day onboard flights throughout the world seems important, but it must be weighed against the 10.5 million international air passengers each day. For comparison, every minute there is about one malaria death worldwide or near 200 tobacco-related deaths each day in France.

The survival rate after a cardiac arrest onboard a flight can be surprising, especially when it is compared to the result of specialized emergency services on the ground. According to data from the French mobile emergency service in 2012, $34 \%$ of patients arrive alive at the hospital, and only $7 \%$ come out alive. ${ }^{21}$ This can be explained in part by the fact that commercial cabin crews are particularly well trained in first aid procedures; they hold a certificate of safety training issued in France by the General Direction of Civil Aviation. They train regularly with practical scenarios. Then, the occurrence of a sudden death can be immediately taken care of onboard, allowing a short no-flow. Furthermore, some companies provide an external automatic defibrillator onboard, essential to treating a rhythm disorder such as ventricular fibrillation, and some aircraft have a space dedicated to the care of an afflicted passenger. ${ }^{11}$ The Australian airline Quantas was the first to equip its aircraft with such equipment in 1992. Currently, regulations differ by country: while US licensed aircraft are required to have an external automatic defibrillator onboard, this is not the case for European licensed aircraft. ${ }^{11}$ Nevertheless, companies can decide to equip their aircrafts with defibrillators, like Air France. 
Diversions are rare, because in most cases, inflight medical events can be resolved either by the cabin crew or by medical/paramedical intervention. Diversion is a big decision that can be made only by the captain, because it can have significant consequences. On a purely financial basis, a diversion can cost up to $\$ 800000$ dollars, not to mention the inconvenience for other passengers. Several elements are taken into consideration when making such a decision, such as the medical point of view, the nature of the event and the capacities of care onboard, and the distance from the nearest airport offering a sufficient medical platform. From the operational aspect, the captain must consider the weather conditions, fuel rate, and geographic location.

\section{Conclusion}

The definition of an inflight medical event deserves to be specified, and the collection of data on these events needs to be standardized, specifying their characteristics and those of the passengers involved. This will help ascertain a better understanding of this issue, and may raise the awareness of passengers with chronic diseases or a fragile health and general practitioners. The frequency of inflight medical events is estimated to be between 120 and 350 events around the world each day. Most of them are not serious, but are mainly lipothymic discomforts and syncope, digestive disorders, cardiorespiratory problems, and neuropsychiatric events. In two-thirds of cases, the inflight medical event is related to a pre-existing pathology, especially cardiorespiratory ones.

\section{Authors' Contributions}

GG and MJ were the main authors of the article. MO revised the article critically concerning intellectual content. PE had the original idea, gave an editorial and scientific advice, and his final approval.

\section{Conflict of Interest Disclosures}

The authors declare that they have no conflicts of interest.

\section{Ethical Approval}

This study complies with current ethical considerations. Ethical issues (including plagiarism, misconduct, data fabrication, falsification, double publication or redundancy) were thoroughly considered by the authors.

\section{Funding/Support}

None.

\section{References}

1. The World Bank Group. Air transport, passengers carried. https:// data.worldbank.org/indicator/is.air.psgr. Accessed January 14, 2018.

2. International Air Transport Association (IATA). Press release: Strong demand for air transport increases in 2014. https://www. iata.org/pressroom/pr/Documents/French-PR-2015-02-05-01.pdf. Accessed January 14, 2018.

3. International Air Transport Association (IATA). Traveler numbers reach new heighs. https://www.iata.org/pressroom/pr/ Pages/2018-09-06-01.aspx. Accessed January 14, 2018.

4. Air Journal. Air transport: 7.2 billion passengers worldwide in 2015. https://www.air-journal.fr/2016-09-11-transport-aerien-72milliards-de-voyageurs-dans-le-monde-en-2015-5169203.html. Accessed January 14, 2018.

5. Air Journal. IATA: 8.2 billion international passengers in 2037! https://www.air-journal.fr/2018-10-25-iata-82-milliards-depassagers-en-2037-5206389.html. Accessed January 14, 2018.

6. Peterson DC, Martin-Gill C, Guyette FX, et al. Outcomes of medical emergencies on commercial airline flights. N Engl J Med. 2013;368(22):2075-2083. doi:10.1056/NEJMoa1212052.

7. Sand M, Bechara FG, Sand D, Mann B. Surgical and medical emergencies on board European aircraft: a retrospective study of 10189 cases. Crit Care. 2009;13(1):R3. doi:10.1186/cc7690.

8. Cummins RO, Schubach JA. Frequency and types of medical emergencies among commercial air travelers. JAMA. 1989;261(9):1295-1299. doi:10.1001/jama.261.9.1295.

9. Szmajer M, Rodriguez P, Sauval P, Charetteur MP, Derossi A, Carli P. Medical assistance during commercial airline flights: analysis of 11 years experience of the Paris Emergency Medical Service (SAMU) between 1989 and 1999. Resuscitation. 2001;50(2):147151. doi:10.1016/S0300-9572(01)00347-1.

10. Rodenberg H. Medical emergencies aboard commercial aircraft. Ann Emerg Med. 1987;16(12):1373-1377. doi:10.1016/S01960644(87)80422-5.

11. Graf J, Stuben U, Pump S. In-flight medical emergencies. Dtsch Arztebl Int. 2012;109(37):591-601; quiz 602. doi:10.3238/ arztebl.2012.0591.

12. Dowdall N. "Is there a doctor on the aircraft?" Top 10 in-flight medical emergencies. BMJ. 2000;321(7272):1336-1337. doi:10.1136/bmj.321.7272.1336.

13. Baker SP, Brady JE, Shanahan DF, Li G. Aviation-related injury morbidity and mortality: data from U.S. health information systems. Aviat Space Environ Med. 2009;80(12):1001-1005. doi:10.3357/ASEM.2575.2009.

14. Qureshi A, Porter KM. Emergencies in the air. Emerg Med J. 2005;22(9):658-659. doi:10.1136/emj.2005.024505.

15. Valani R, Cornacchia M, Kube D. Flight diversions due to onboard medical emergencies on an international commercial airline. Aviat Space Environ Med. 2010;81(11):1037-1040. doi:10.3357/ ASEM.2789.2010.

16. O'Rourke MF, Donaldson E, Geddes JS. An airline cardiac arrest program. Circulation. 1997;96(9):2849-2853. doi:10.1161/01. cir.96.9.2849.

17. Brown AM, Rittenberger JC, Ammon CM, Harrington S, Guyette FX. In-flight automated external defibrillator use and consultation patterns. Prehosp Emerg Care. 2010;14(2):235-239. doi:10.3109/10903120903572319.

18. Nable JV, Tupe CL, Gehle BD, Brady WJ. In-Flight Medical Emergencies during Commercial Travel. $N$ Engl J Med. 2015;373(10):939-945. doi:10.1056/NEJMra1409213.

19. Gendreau MA, Dejohn C. Responding to medical events during commercial airline flights. N Engl J Med. 2002;346(14):10671073. doi:10.1056/NEJMra012774.

20. Select Committee on Science and Technology. Air travel and health: fifth report. London: United Kingdom House of Lords; 2000.

21. Bougouin W, Lamhaut L, Marijon E, et al. Incidence, characteristics and outcome of sudden cardiac death in France. Eur Heart J. 2013;34 Suppl 1:1743. doi:10.1093/eurheartj/eht308.1743. 